\title{
Association between surges of follicle-stimulating hormone and the emergence of follicular waves in heifers
}

\author{
G. P. Adams ${ }^{1}$, R. L. Matteri ${ }^{2}$, J. P. Kastelic ${ }^{1}$, J. C. H. Ko ${ }^{1}$ and \\ O. J. Ginther ${ }^{1 *}$ \\ ${ }^{1}$ Department of Veterinary Science and ${ }^{2}$ Department of Meat and Animal Science, \\ University of Wisconsin, Madison, WI 53706, USA
}

\begin{abstract}
Summary. The effects of ablation of a dominant follicle and treatment with follicular fluid on circulating concentrations of follicle-stimulating hormone (FSH) were studied and the temporal relationships between surges of FSH and follicular waves were studied in heifers with two or three follicular waves/interovulatory interval. Cauterization of the dominant follicle on Day 3 or Day 5 (ovulation on Day 0 ) (six control and six treated heifers/day) resulted in a surge $(P<0.05)$ in FSH beginning the day after cautery. The FSH surge prior to wave 2 (first post-treatment follicular wave) occurred 4 days (Day 3 cautery) and 2 days (Day 5 cautery) before the surge in control groups, corresponding to a 4-day and a 2-day advance in emergence of wave 2 compared with controls. It was concluded that the dominant follicle on Day 3 and Day 5 was associated with the suppression of circulating FSH concentrations. Heifers $(n=4 /$ group) were untreated or treated intravenously with a proteinaceous fraction of bovine follicular fluid on Days 0-3, 3-6, or 6-11. Concentrations of FSH were suppressed $(P<0.05)$ for the duration of treatment, regardless of the days of treatment. Cessation of treatment was followed within 1 day by the start of a surge in FSH. The FSH surge prior to wave 2 occurred 2 days earlier (treatment on Days 0-3), 1 day later (treatment on Days 3-6), and 6 days later (treatment on Days 6-11) than in controls, corresponding to an equivalent advance or delay, respectively, in the emergence of wave 2 compared with controls. The results suggest that the effects of exogenous follicular fluid on follicular development were mediated, in whole or in part, by altering plasma FSH concentrations. Control heifers combined for the two experiments were separated into those with 2 -wave $(n=11)$ or 3 -wave $(n=5)$ interovulatory intervals. Two-wave heifers had two FSH surges and 3-wave heifers had three apparent FSH surges during the interovulatory interval. Results of the cautery and follicular fluid experiments indicated that a surge in FSH necessarily preceded the emergence of a wave. The FSH surges in treated and control heifers began 2-4 days before the detectable (ultrasound) emergence of a follicular wave (follicles of 4 and $5 \mathrm{~mm}$ ), peaked 1 or 2 days before emergence and began to decrease approximately when the follicles of a wave begin to diverge into a dominant follicle and subordinate follicles (follicles 6-7 mm).
\end{abstract}

Keywords: FSH; follicles; follicular waves; follicular fluid; inhibin; heifer

\section{Introduction}

A wave of ovarian follicular growth in cattle involves the synchronous development of a group of follicles - a dominant follicle and several subordinates (Savio et al., 1988; Sirois \& Fortune, 1988; 
Knopf et al., 1989). Transrectal ultrasonic imaging shows that most oestrous cycles have two or three follicular waves. For 2-wave oestrous cycles, the detectable emergence of successive waves occurred on Days 0 (day of ovulation) and 10, and for 3-wave cycles, emergence occurred on Days 0 , 9 and 16 (Ginther et al., 1989c). The follicle destined to ovulate was the dominant follicle of the second wave (2-wave cycles) or third wave (3-wave cycles). Within 3 or 4 days after emergence of a wave, subordinate follicles ceased to grow and the dominant anovulatory follicle of the previous wave began to regress (Ginther et al., 1989a). Temporal relationships suggested that the growingphase dominant follicle caused regression of its subordinates and the previous dominant follicle and delayed the emergence of the next follicular wave.

Follicle-stimulating hormone (FSH) plays an important role in the control of follicular growth in cattle (reviewed by Ireland, 1987), but the temporal relationship between surges in circulating FSH concentrations and the emergence of successive follicular waves has not been demonstrated. Two surges in plasma FSH concentration during the bovine oestrous cycle have been reported; the first was coincident with the preovulatory surge in luteinizing hormone (LH) and the second commenced 18-24 h after the onset of the preovulatory LH surge (Dobson, 1978; Walters \& Schallenberger, 1984; Quirk \& Fortune, 1986). Insignificant fluctuations in FSH during the luteal phase have been reported (Akbar et al., 1974; Cheng, 1978; Bolt \& Rollins, 1983; Findlay \& Clarke, 1987), but, after luteolysis, FSH concentrations decreased until the preovulatory surge (Roche \& Ireland, 1981; Butler et al., 1983; Schallenberger et al., 1984, 1985; Quirk \& Fortune, 1986). Increases at intervals of $\sim 4$ days have also been reported (Schams \& Schallenberger, 1976).

There is increasing support for the concept that inhibitory and stimulatory ovarian factors modulate follicular development through the regulation of gonadotrophins and follicular responsiveness to gonadotrophins (Ireland, 1987; Tonetta \& deZerega, 1989). Studies using follicle monitoring (Ginther et al., 1989c), follicle cauterization (Matton et al., 1981) or unilateral ovary removal (Staigmiller \& England, 1982) indicated that a single large follicle inhibits the development of other small follicles. It has been concluded that the inhibitory factor(s) produced by the dominant follicle suppresses other follicles through systemic endocrine channels rather than through intraovarian autocrine or paracrine channels; no intraovarian relationships between follicles were detected (Ginther et al., 1989b). Bovine follicular fluid contains the glycoprotein inhibin (Robertson et al., 1985), which selectively suppresses synthesis and secretion of FSH (reviewed in deKretser \& Robertson, 1989). In early studies (Miller et al., 1979), intravenous administration of a proteinaceous fraction of bovine follicular fluid suppressed follicular activity and delayed oestrus in heifers. Subsequent studies supported these results and showed that follicular fluid suppressed concentration of FSH in plasma without altering plasma LH in ovariectomized (Ireland et al., 1983) and intact (Quirk \& Fortune, 1986) heifers. One study, however, showed no significant suppression of circulating FSH after treatment with follicular fluid (Johnson \& Smith, 1985).

The plasma samples used in the present studies originated from two previously reported experiments. In one cauterizing the dominant follicle of wave 1 (first wave of the interovulatory interval) at Day 3 or Day 5 (Ko et al., 1991), resulted in early emergence of wave 2 and supported the hypothesis that a dominant follicle, during its growing phase, suppresses the emergence of the next wave. The other study examined the effects of administration of a proteinaceous fraction of follicular fluid on Days 0-3, Days 3-6, or Days 6-11 (Kastelic et al., 1990). Follicles that were in the growing phase stopped growing and started to regress, on average, 1 day and 5 days, respectively, after the start of treatment with follicular fluid. The next wave was detected $\sim 3$ days after treatment was stopped.

Plasma samples collected during these two studies were not analysed previously for FSH because of the unavailability of an FSH assay in our laboratories. An assay has since been established and results of assaying the previously collected samples are reported herein. The present study characterized the effects of follicle cautery (Expt 1) and treatment with follicular fluid (Expt 2) on circulating FSH concentrations. Knowledge of the effects of treatment was then used to aid 
interpretation of the temporal associations between changes in FSH concentrations (surges) and the emergence of follicular waves for 2-wave and 3-wave interovulatory intervals (Expt 3).

\section{Materials and Methods}

Nulliparous Holstein heifers, $1 \cdot 52 \cdot 5$ years old and weighing $330-650 \mathrm{~kg}$, were studied during February and March. The follicular responses to cauterization of the dominant follicle and administration of follicular fluid, as previously reported (Kastelic et al., 1990; Ko et al., 1991) were examined in relation to circulating concentrations of FSH. Occasionally, however, it was necessary to inspect or analyse certain aspects of the follicular data to aid interpretation of the results of the FSH assay.

Blood was collected from the tail vein into heparinized tubes; within $1 \mathrm{~h}$, samples were centrifuged at $1000 \mathrm{~g}$ for 15 min and plasma was aspirated and stored in a freezer at $-20^{\circ} \mathrm{C}$. Concentrations of FSH in plasma were determined by a modification of the previously validated radioimmunoassay of Bolt \& Rollins (1983). Iodination- and referencegrade bFSH (USDA-FSH-BP3 and USDA-bFSH-B-1, respectively) and specific antiserum to bFSH (USDA-5-pool) were provided by the USDA Animal Hormone Program. Iodination of bFSH was performed with Iodogen (1,3,4,6tetrachloro-3-alpha, 6-alpha-diphenylglycouril; Pierce Chemical Co., Rockford, IL, USA) as described (Matteri et al., 1987). Assay buffers were phosphate-buffered saline (PBS; $0.01 \mathrm{~mol}$ sodium phosphate $/ 1,0 \cdot 15 \mathrm{~mol}$ sodium chloride $/ 1$, $0.1 \%$ sodium azide, $\mathrm{pH} 7.0$ ) and PBS with $0.1 \%$ gelatin) (PBS-gel); $200 \mu \mathrm{l}$ of plasma, $300 \mu \mathrm{l}$ PBS-gel and $200 \mu \mathrm{l}$ of the primary antibody (1:15000 dilution in PBS-gel, with $2.5 \%$ normal rabbit serum) were added in $12 \times 75 \mathrm{~mm}$ borosilicate glass tubes on the first day of the assay. After $24 \mathrm{~h}$ of incubation at room temperature, $100 \mu \mathrm{l}$ of radioligand ( 20000 c.p.m. in PBS-gel) was added. Incubation continued for $48 \mathrm{~h}$ at room temperature and then $50 \mu \mathrm{l}$ of sheep anti-rabbit IgG serum was added. The immunoprecipitate was allowed to form at room temperature for a minimum of $6 \mathrm{~h}$. The assay tubes were then centrifuged for $30 \mathrm{~min}$ at $1200 \mathrm{~g}$. The supernatant was aspirated and the radioactivity in the pellets was counted for gamma decay. Assay data analysis was performed by weighted leastsquares regression (Rodbard \& Lewald, 1970). The minimum detectable level of USDA-bFSH-B-1 was $1 \mathrm{ng} / \mathrm{tube}$ ( $5 \mathrm{ng} / \mathrm{ml}$ plasma). This detection limit and the peak and trough values of plasma FSH, were similar to those previously reported with the same immunoreagents (Turzillo \& Fortune, 1990). Between- and within-assay coefficients of variation were 9 and $5 \%$, respectively (Rodbard, 1974). Plasma samples from individual animals were analysed within a single assay. As reported earlier (Bolt \& Rollins, 1983), increasing volumes of plasma of ovariectomized heifers $(25-200 \mu \mathrm{l})$ produced displacement of radioligand that paralleled the standard curve. The day of maximum FSH concentration prior to each follicular wave was defined as the day of highest FSH concentration within 5 days of emergence of a wave. The day of initial increase in FSH concentration prior to each follicular wave was defined as the first day that two sequential increases lead to the maximum concentration. A significant rise and fall in mean plasma FSH concentration was retrospectively defined as an FSH surge.

\section{Experiment 1}

Twenty-four heifers were randomly assigned to the following four groups $(n=6$ per group): cautery of the dominant follicle on Day 3, sham surgery on Day 3, cautery of the dominant follicle on Day 5 and sham surgery on Day 5 as described (Ko et al., 1991). In the cautery groups, blood samples were taken once a day from 1 day before surgery to the day of post-treatment ovulation. In the sham groups, blood samples were taken daily throughout the interovulatory interval.

\section{Experiment 2}

Sixteen heifers were randomly assigned to the following four groups ( $n=4$ per group) as described (Kastelic et al., 1990): untreated controls and intravenous treatment with a proteinaceous fraction of bovine follicular fluid on Days $0-3$, Days 3-6 and Days 6-11. The proteinaceous fraction of follicular fluid was injected intravenously at 12-h intervals. In the treated heifers, blood samples were collected immediately before administration of follicular fluid, starting on the day of treatment to the fourth day after treatment (i.e. Days 0-7, Days 3-10 and Days 6-15, respectively). In the controls, blood samples were taken daily from Day 0-Day 15.

\section{Experiment 3}

To characterize the temporal relationships between circulating FSH concentrations (surges) and follicular growth and regression (waves) during an interovulatory interval, data from control heifers in Expts 1 and 2 were used.

\section{Statistical analyses}

In Expts 1 and 2, the following end points were compared among groups by analyses of variance: the day of initial increase in FSH concentration prior to the emergence of each follicular wave, the day of maximum FSH concentration prior to each wave, and the intervals (days) between the end of treatment (day of cautery or last day of 
follicular fluid treatment) and the initial increase in FSH concentration and to the maximum FSH concentration. Mean FSH concentrations for each treatment group were plotted against those of the respective control group. Splitplot analyses of variance were used to determine the main effects of day and group, and the day $\times$ group interaction for changes in FSH concentration. Student's $t$ tests were used to determine differences between control and treatment groups within days if a significant difference was detected in the overall analysis of variance. Post-treatment effect on FSH concentration was determined by split-plot analysis of variance starting on the day of cautery (Expt 1) or the last day of treatment with follicular fluid (Expt 2).

In Expt 3, heifers with two follicular waves during the interovulatory interval were compared with those that had three waves, by analyses of variance for the day of initial increase in FSH prior to wave 2 and day of maximum FSH concentrations prior to wave 2 . Follicle data were normalized to the mean day of detection of the dominant follicle (follicle diameter 4-5 mm) as described (Ginther et al., 1989c); FSH data for each heifer were normalized by using the follicle data for the corresponding day. Split-plot analyses of variance were performed on follicle data to determine differences between the two control groups in Expt 1 and subsequently to determine main effects of day and experiment, and day $\times$ experiment interaction in control heifers from Expts 1 and 2. When no differences between control groups and between experiments were detected, follicle data and FSH data were combined to illustrate composite means over the interovulatory interval. Differences in FSH concentrations among days were compared by the method of least-significant difference within 2-wave and 3-wave cycles if overall analyses of variance indicated a day effect.

\section{Results}

\section{Experiment 1}

Within each end point, differences among groups in responses in FSH concentration to cautery of the dominant follicle of wave 1 were detected only for wave 2 (first post-treatment wave; Table 1). The initial increase in FSH and maximum FSH concentration occurred earliest in the group subjected to cautery on Day 3, intermediate in the Day-5 cautery group and latest in the control groups $(P<0.05)$. Mean FSH concentrations and the reported day of emergence of wave 2 with the results of statistical analyses are shown for the period starting before cautery to 7 days after cautery (Fig. 1). For both days of cautery, mean concentration of FSH was higher $(P<0.05)$ on the day after cautery than for the corresponding day in control heifers. The effect of follicle cautery on FSH concentration was not different for cautery on Day 3 vs. Day 5 and data were combined (Fig. 2). There was no difference between groups subjected to cautery on Day 3 or Day 5 in the intervals from cauterization to (i) initial increase in FSH concentration $(1 \cdot 1 \pm 0 \cdot 1$ days average over both groups), (ii) maximum FSH concentration ( $2 \cdot 0 \pm 0 \cdot 2$ days) and (iii) emergence of a post-treatment follicular wave $(2 \cdot 3 \pm 0 \cdot 2$ days; Table 1$)$.

\section{Experiment 2}

Within each end point, differences among groups treated with a proteinaceous fraction of follicular fluid were detected only for wave 2 (Table 2). The initial increase in FSH concentrations and maximum FSH concentrations occurred earliest in heifers treated on Days 0-3, intermediate in control heifers and those treated on Days 3-6, and latest in heifers treated on Days 6-11 $(P<0.05)$. Only the initial rise in FSH was delayed $(P<0.05)$ in heifers treated on Days 3-6 compared with control heifers. Mean FSH concentrations, the reported day of emergence of follicular wave 2 , and the results of statistical analyses are shown for the period starting on the day of treatment to 5 days after treatment (Fig. 3). Mean FSH concentrations averaged over days were lower $(P<0.05)$ in the treatment groups during the period of treatment compared with the respective periods in the control groups (Days $0-3,6.5 \pm 0.3 \mathrm{ng} / \mathrm{ml}$ vs. $9.9 \pm 0.6 \mathrm{ng} / \mathrm{ml}$; Days 3-6, $8.2 \pm 0.4 \mathrm{ng} / \mathrm{ml}$ vs. $9.3 \pm 0.4 \mathrm{ng} / \mathrm{ml}$; Days $6-11,6 \cdot 1 \pm 0.3 \mathrm{ng} / \mathrm{ml}$ vs. $10.0 \pm 0.5 \mathrm{ng} / \mathrm{ml}$ for treated vs. control heifers, respectively). There was no difference among treatment groups in the effect of follicular fluid on FSH concentration and therefore data were combined (Fig. 4). There was no difference among treatment groups in mean interval from (i) the end of treatment to initial increase in FSH concentration ( $1 \cdot 1 \pm 0 \cdot 1$ days averaged over the three groups), (ii) maximum FSH concentration $(2 \cdot 2 \pm 0 \cdot 2$ days $)$ and (iii) the emergence of a follicular wave ( $3 \cdot 2 \pm 0 \cdot 3$ days; Table 2$)$. 
Table 1. Effect of cauterization of the dominant follicle of wave 1 at Day 3 and 5 on the emergence of subsequent dominant follicles and concentrations of follicle-stimulating hormone (FSH) in association with each follicular wave in heifers (Expt 1; mean \pm s.e.m.; number of heifers in parentheses)

\begin{tabular}{|c|c|c|c|c|}
\hline \multirow[b]{2}{*}{ End point } & \multicolumn{2}{|c|}{ Day 3} & \multicolumn{2}{|c|}{ Day 5} \\
\hline & Control & Cautery & Control & Cautery \\
\hline \multicolumn{5}{|c|}{ Day of emergence of the dominant follicle of ${ }^{\mathrm{a}}$} \\
\hline Wave 1 & $0.6 \pm 0.8(6)$ & $0 \cdot 1 \pm 0 \cdot 1(6)$ & $0.1 \pm 0.3(6)$ & $0 \cdot 1 \pm 0 \cdot 3(6)$ \\
\hline $2^{b}$ & $9.7 \pm 0.7(6)^{c}$ & $5.5 \pm 0.2(6)^{\mathrm{c}}$ & $9 \cdot 2 \pm 0.5(6)^{c}$ & $7 \cdot 0 \pm 0 \cdot 3(6)^{d}$ \\
\hline 3 & $17.0(1)$ & $13.2 \pm 0.9(6)$ & $16 \cdot 0 \pm 1 \cdot 0(2)$ & $14 \cdot 8 \pm 0 \cdot 7(5)$ \\
\hline 4 & - & $17 \cdot 0 \pm 1 \cdot 5(2)$ & - & - \\
\hline \multicolumn{5}{|c|}{ Day of initial increase in FSH prior to } \\
\hline Wave $2^{b}$ & $7.5 \pm 0.8(6)^{\mathrm{c}}$ & $4 \cdot 2 \pm 0 \cdot 2(6)^{\mathrm{e}}$ & $7 \cdot 6 \pm 0.5(6)^{\mathrm{c}}$ & $6 \cdot 0 \pm 0.0(5)^{\mathrm{d}}$ \\
\hline 3 & $15 \cdot 0(1)$ & $12 \cdot 3 \pm 0 \cdot 6(6)$ & $14 \cdot 0 \pm 2 \cdot 0(2)$ & $13 \cdot 6 \pm 0.5(5)$ \\
\hline 4 & - & $16.0 \pm 2 \cdot 0(2)$ & - & - \\
\hline \multicolumn{5}{|c|}{ Day of maximum FSH prior to } \\
\hline Wave $2^{\text {b }}$ & $9 \cdot 0 \pm 0.5(6)^{\mathrm{c}}$ & $4 \cdot 3 \pm 0 \cdot 2(6)^{\mathrm{e}}$ & $8.5 \pm 0.6(6)^{c}$ & $6 \cdot 5 \pm 0 \cdot 3(4)^{d}$ \\
\hline 3 & $16 \cdot 0(1)$ & $12 \cdot 5 \pm 1 \cdot 1(6)$ & $15 \cdot 0 \pm 1 \cdot 0(2)$ & $14 \cdot 6 \pm 0 \cdot 7(5)$ \\
\hline 4 & - & $16 \cdot 5 \pm 2 \cdot 5(2)$ & - & - \\
\hline \multicolumn{5}{|c|}{ Interval (days) from cauterization to } \\
\hline \multicolumn{2}{|c|}{ Initial increase in FSH } & $1 \cdot 2 \pm 0 \cdot 2(6)$ & & $1 \cdot 0 \pm 0 \cdot 0(5)$ \\
\hline \multicolumn{2}{|c|}{ Maximum FSH } & $2 \cdot 0 \pm 0 \cdot 4(6)$ & & $2 \cdot 0 \pm 0 \cdot 3(5)$ \\
\hline \multicolumn{2}{|c|}{ Emergence of a follicular wave ${ }^{a}$} & $2 \cdot 5 \pm 0 \cdot 2(6)$ & & $2 \cdot 0 \pm 0 \cdot 3(6)$ \\
\hline
\end{tabular}

${ }^{\mathrm{a}}$ Follicle data from the previous reports that are repeated herein for comparison with the FSH data.

${ }^{\text {b Group effect, } P<0.0 \text { l. }}$

c.d.e Within each end point, values with different superscripts are different $(P<0.05)$.

\section{Experiment 3}

The proportions of heifers with two and three follicular waves during the interovulatory interval and day of emergence and diameters of the dominant follicle of each wave were not different between control groups of Expt 1 (Ko et al., 1991) and Expt 2 (Kastelic et al., 1990) and data were combined (Table 3; Fig. 5). The intervals from initial increase in FSH to emergence of the dominant follicle of each wave $(2 \cdot 1 \pm 0 \cdot 3$ days) and from maximum FSH to emergence of the dominant follicle of each wave $(0 \cdot 7 \pm 0 \cdot 2$ days) were not different between 2- and 3-wave heifers or between the second and third waves in 3 -wave heifers. There was an effect of day $(P<0.0001)$ on the normalized FSH concentrations over the interovulatory interval for the 2-wave, but not for the 3-wave, heifers. Within the 2-wave heifers, the differences in FSH values were significant as follows: decrease between Days 0 and 4, increase between Days 4 and 9, decrease between Days 9 and 14, and increase between Days 14 and 19. The interovulatory interval was shorter $(P<0.01)$ for 2 -wave heifers $(20.3 \pm 0.4$ days) than for 3 -wave heifers $(23.3 \pm 0.9$ days). The temporal relationships between changes in plasma FSH concentration and the reported emergence and growth of successive dominant follicles are illustrated (Fig. 5).

\section{Discussion}

Cautery of the dominant follicle of wave 1 on Day 3 delayed the onset of regression of subordinate follicles of wave 1; cautery on Day 3 or 5 resulted in early emergence of wave 2 (Ko et al., 1991). Results of the present study indicated that the presence of the Day 3 and Day 5 dominant follicle was associated with the suppression of circulating FSH concentrations. Ablation of the dominant follicle on Day 3 or 5 relieved the suppression evinced by a surge in FSH beginning the day after 


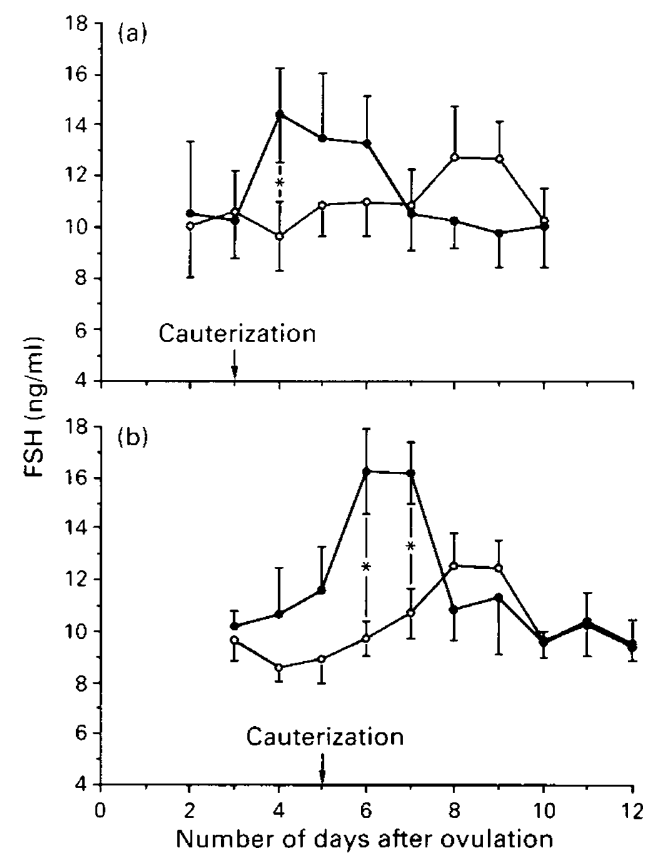

Fig. 1. Concentrations of follicle-stimulating hormone (FSH) and results of statistical analyses in control heifers $(O, n=6)$ and those in which the dominant follicle of wave 1 was cauterized (,$n=6$ ) on (a) Day 3 or (b) Day 5; Expt $1 .{ }^{*}$ Significant difference in concentrations between the cauterized group and sham-operated controls; day, $P<0.0001$; treatment, NS; day $\times$ treatment, $P<0.0001$.

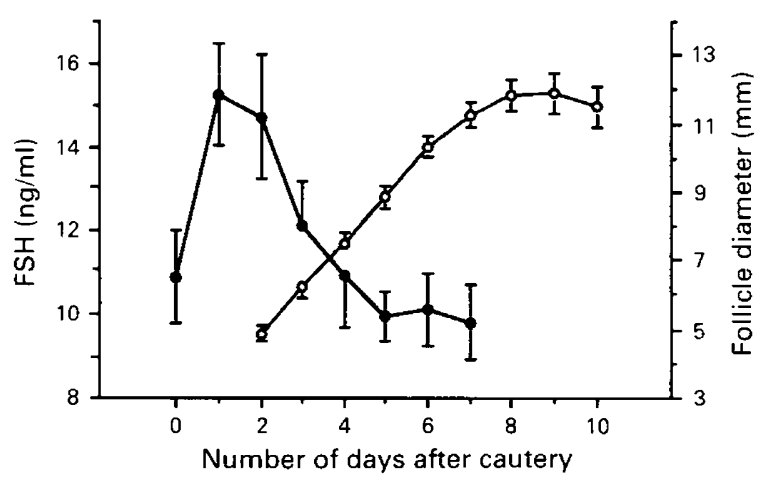

Fig. 2. Relationship between follicle-stimulating hormone (FSH) concentrations after cautery (O) and growth of the dominant follicle $(O)$ of the follicular wave following cautery $(n=12)$. The FSH concentrations did not differ between Day 3 and Day 5 cautery groups and the combined profile is shown. The first significant decrease in FSH occurred between the first and second day after detection of the emergence of the post-cautery follicular wave.

cautery. The FSH surge spanned 2 or 3 days; concentration was maximal 2 days after cautery and returned to precautery levels by $4-5$ days after cautery. The surge in FSH after cautery on Day 3 was probably responsible for the apparent resurgence of some subordinate follicles of wave 1 and the delayed regression of others as previously reported (Ko et al., 1991). The FSH surge after cautery on Day 3 or 5 was probably responsible for hastening the onset of the next wave. On average, FSH 
Table 2. Effect of intravenous administration of follicular fluid on the day of emergence of the dominant follicle and concentration of follicle-stimulating hormone (FSH) in association with each follicular wave in heifers (Expt 2; mean \pm s.e.m.; number of heifers in parentheses)

\begin{tabular}{|c|c|c|c|c|}
\hline \multirow[b]{2}{*}{ End point } & \multirow[b]{2}{*}{ Control } & \multicolumn{3}{|c|}{ Treatment with follicular fluid on } \\
\hline & & Days $0-3$ & Days 3-6 & Days 6-11 \\
\hline \multicolumn{5}{|c|}{ Day of emergence of the dominant follicle of ${ }^{a}$} \\
\hline Wave 1 & $0 \cdot 0 \pm 0 \cdot 0(4)$ & $0.0 \pm 0.0(4)$ & $0 \cdot 2 \pm 0.2(4)$ & $0.2 \pm 0.5(4)$ \\
\hline $2^{b}$ & $8.8 \pm 0.5(4)^{\mathrm{c}}$ & $6.0 \pm 0.4(4)^{\mathrm{d}}$ & $9 \cdot 8 \pm 0.5(4)^{\mathrm{c}}$ & $14.3 \pm 0.3(4)^{e}$ \\
\hline 3 & $15.0(1)$ & $14.5 \pm 0.9(4)$ & $16.7 \pm 0.9(3)$ & - \\
\hline \multicolumn{5}{|c|}{ Day of initial increase in FSH prior to } \\
\hline Wave $2^{\mathrm{b}}$ & $6 \cdot 5 \pm 0.4(4)^{\mathrm{c}}$ & $4 \cdot 1 \pm 0 \cdot 1(4)^{d}$ & $7 \cdot 9 \pm 0.2(4)^{e}$ & $12 \cdot 8 \pm 0 \cdot 3(4)^{\mathrm{f}}$ \\
\hline & $14 \cdot 2 \pm 0 \cdot 9(3)$ & - & - & - \\
\hline \multicolumn{5}{|c|}{ Day of maximum FSH prior to } \\
\hline Wave $2^{\mathrm{b}}$ & $8 \cdot 0 \pm 0.4(4)^{\mathrm{c}}$ & $5 \cdot 6 \pm 0 \cdot 5(4)^{d}$ & $8 \cdot 8 \pm 0 \cdot 1(4)^{\mathrm{c}}$ & $13.8 \pm 0.6(4)^{\mathrm{c}}$ \\
\hline 3 & $<15 \cdot 5(1)$ & - & - & - \\
\hline \multicolumn{5}{|c|}{ Interval (days) from end of treatment to } \\
\hline Initial in & in $\mathrm{FSH}$ & $0 \cdot 6 \pm 0 \cdot 1(4)$ & $1.4 \pm 0.2(4)$ & $1 \cdot 3 \pm 0.3(4)$ \\
\hline Maximu & & $2 \cdot 1 \pm 0.5(4)$ & $2 \cdot 1 \pm 0 \cdot 2(4)$ & $2 \cdot 3 \pm 0.2(4)$ \\
\hline Emergen & a follicular wave $\mathrm{a}^{\mathrm{a}}$ & $2 \cdot 5 \pm 0 \cdot 6(4)$ & $3 \cdot 8 \pm 0 \cdot 5(4)$ & $3 \cdot 3 \pm 0 \cdot 3(4)$ \\
\hline
\end{tabular}

${ }^{a}$ Follicle data from the previous reports that are repeated herein for comparison with the FSH data. bGroup effect, $P<0.001$.

c.d.e.f Within each end point, values with different superscripts are different $(P<0 \cdot 05)$.

surges prior to the first follicular wave after cautery occurred 4 days (Day 3 cautery) and 2 days (Day 5 cautery) before the surge in control groups, corresponding to a 4-day and a 2-day advance in day of emergence of the post-cautery wave.

Intravenous administration of a proteinaceous fraction of follicular fluid has been shown to suppress plasma FSH concentrations (Quirk \& Fortune, 1986). The results of Expt 2 suggested that the effects of exogenous follicular fluid on follicular development were mediated, in whole or in part, by altering plasma FSH concentrations. Treatment suppressed circulating FSH concentrations for the duration of treatment, regardless of the time of treatment. Cessation of treatment was followed by a surge in FSH beginning, on average, 1 day and peaking 2 days, after the end of treatment, regardless of the time of treatment. For wave 2 of the controls and the treated heifers (first post-treatment follicular wave), the start of the FSH surge occurred, on average, 2 days before the detectable emergence of the wave. The FSH surge prior to the follicular wave in the treatment groups occurred 2 days earlier (treatment on Days 0-3), 1 day later (treatment on Days 3-6) and 6 days later (treatment on Days 6-11) than in the control groups.

Preliminary analysis of the FSH profile during an interovulatory interval in control heifers (Expt 3) without regard to the number of follicular waves per heifer per cycle indicated that, on average, two surges $(P<0.05)$ occurred: one around the time of ovulation and the second during the midluteal phase. However, when heifers were separated according to two vs. three follicular waves during the interovulatory interval, 2-wave heifers had two significant surges in FSH and 3-wave heifers had three apparent surges. These results demonstrated that combining all heifers into one group masked a third surge of FSH in 3-wave heifers, similar to what occurs when follicular waves are studied without partitioning heifers according to number of waves (Ginther et al., 1989a). Despite FSH changes of similar magnitude in 3-wave heifers and 2-wave heifers, the apparent surges did not reach significance for 3-wave heifers. The standard error was greater in the 3-wave group, probably as a result of there being few heifers. The data were analysed retrospectively to test for a difference in FSH concentration between 2-wave vs. 3-wave heifers from Day 10 to Day 20 (Fig. 5). There was a significant day $\times$ wave interaction $(P<0.03)$ attributable to 


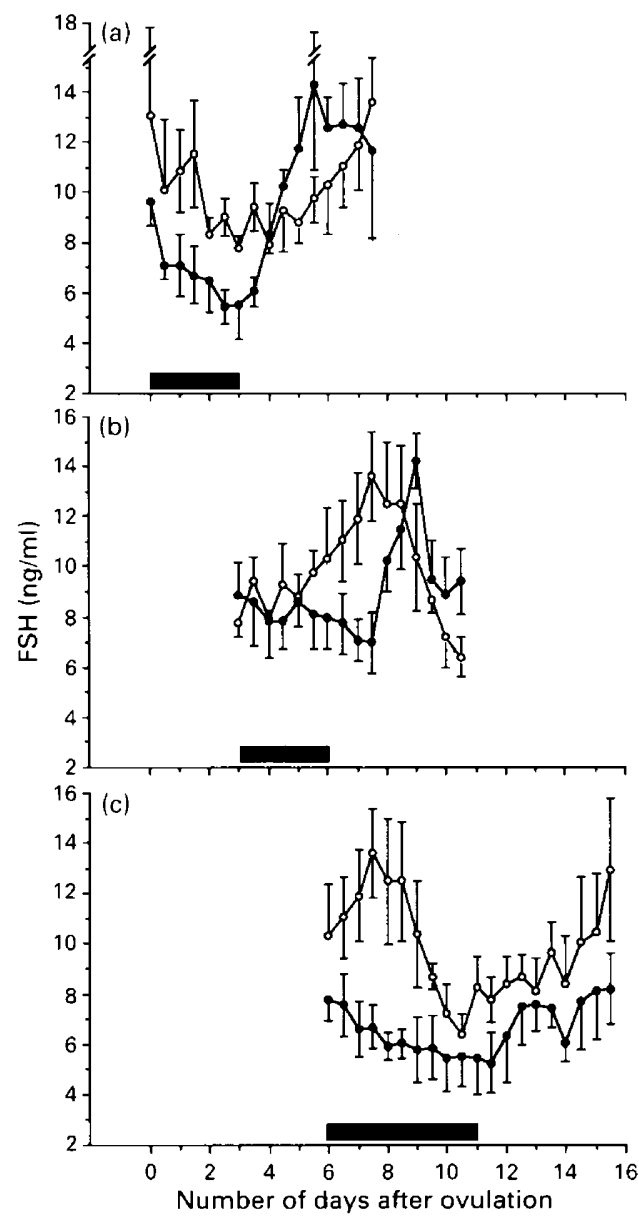

Fig. 3. Concentrations of follicle-stimulating hormone (FSH) and results of statistical analyses in heifers treated with a proteinaceous fraction of follicular fluid $(\boldsymbol{O})$ on the indicated days ( D) $(n=4)$ and controls $(O)(n=4)($ Expt 2$)$ (a) day, $P<0.0001$; treatment, NS; day $\times$ treatment, $P<0.001$; (b) day, $P<0.0003$; treatment, NS; day $\times$ treatment, $P<0.003$; (c) day, $P<0.006$; treatment, $P<0.03$; day $\times$ treatment, NS.

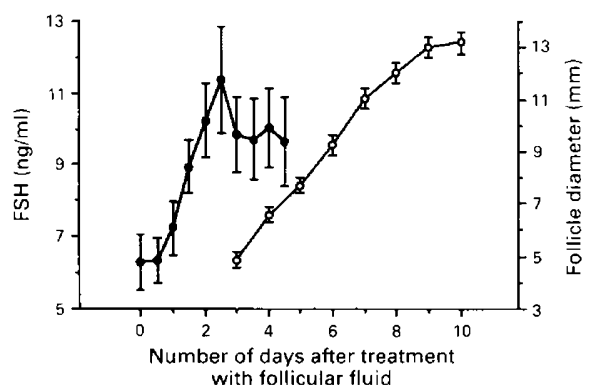

Fig. 4. Relationship between profile of follicle-stimulating hormone (FSH, $\bullet$ ) after the last day of treatment with follicular fluid and the emergence and growth of the dominant follicle $(O)$ of the first post-treatment follicular wave $(n=12)$ (Expt 2$)$. The FSH concentrations did not differ among treatment groups (treatment on Days 0-3, 3-6 and 6-11) and the combined data are shown. 
Table 3. Days (mean \pm s.e.m.; number of heifers in parentheses) of detection of a follicular wave and initial increase in the concentration of plasma follicle-stimulating hormone (FSH) in control heifers with two or three interovulatory waves (Expt 3)

\begin{tabular}{|c|c|c|c|c|c|}
\hline \multirow[b]{2}{*}{ End point } & \multicolumn{2}{|c|}{ 2-wave heifers } & \multicolumn{3}{|c|}{ 3-wave heifers } \\
\hline & Wave 1 & Wave 2 & Wave I & Wave 2 & Wave 3 \\
\hline $\begin{array}{l}\text { Day of emergence } \\
\text { of follicular wave }\end{array}$ & $0.2 \pm 0 \cdot 1(11)$ & $9 \cdot 6 \pm 0.4(11)^{a}$ & $0.4 \pm 0.4(5)$ & $8 \cdot 2 \pm 0 \cdot 2(5)^{b}$ & $16 \cdot 0 \pm 0 \cdot 6(5)$ \\
\hline Day of FSH increase & - & $7 \cdot 6 \pm 0.4(11)^{\mathrm{a}}$ & - & $5.9 \pm 0.6(5)^{\mathrm{b}}$ & $13 \cdot 9 \pm 0 \cdot 7(5)$ \\
\hline Day of maximum FSH & - & $8.9 \pm 0.4(11)^{x}$ & - & $7 \cdot 8 \pm 0 \cdot 2(5)^{y}$ & $15 \cdot 1 \pm 0.5(5)$ \\
\hline
\end{tabular}

a.bWithin each end point values with different superscripts were different $(P<0.05)$.

${ }^{x . y}$ Values with different superscripts tended to differ $(P=0.08)$.

(a) 2-wave interovulatory intervals $(n=11)$

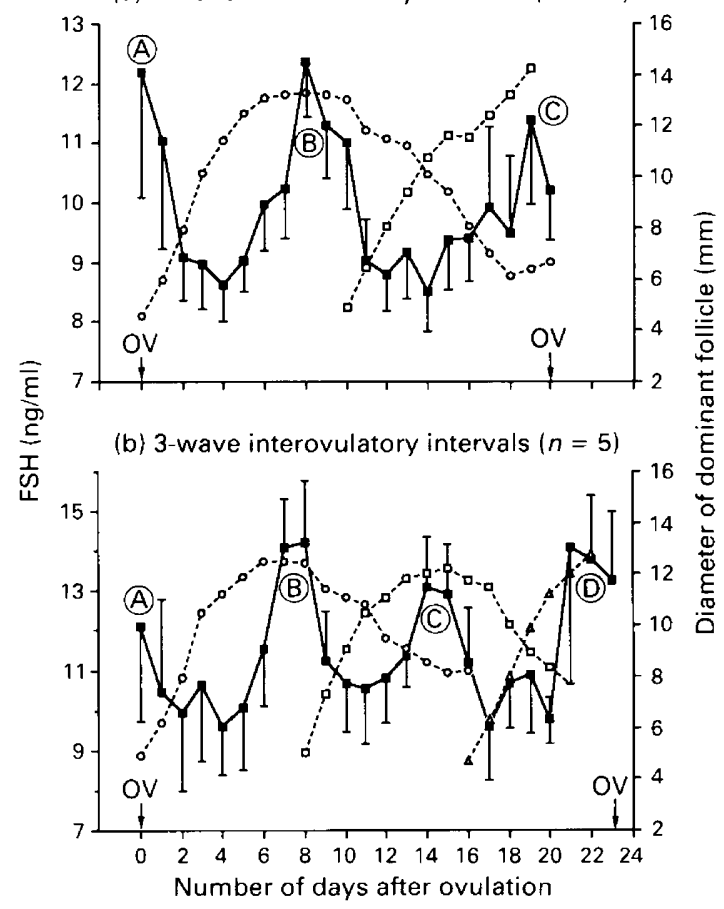

Fig. 5. Experiment 3. Relationship between profiles of follicle-stimulating hormone (FSH, $\mathbf{\square})$ and the growth of the dominant follicle (---) for control heifers with (a) two and (b) three follicular waves. The follicle data are normalized to the mean lengths of the interovulatory intervals (lengths significantly different between 2-wave and 3-wave heifers) and to the mean day of emergence of each wave. The day of FSH values correspond to the normalized day of the follicle values. (a) A = decline of FSH surge ( $\boldsymbol{\square})$ for follicular wave $1(\mathrm{O})$; B $=$ FSH surge for follicular wave $2(\square)$ (ovulatory wave); $\mathrm{C}=$ first portion of FSH surge for the next postovulatory follicular wave. (b) $\mathrm{A}=$ decline of FSH surge ( $\mathbf{a})$ for follicular wave $1(\mathrm{O})$; $\mathbf{B}=\mathrm{FSH}$ surge for follicular wave $2(\square)$ (anovulatory wave); $\mathrm{C}=\mathrm{FSH}$ surge for follicular wave $3(\triangle)$ (ovulatory wave); $\mathrm{D}=$ first portion of FSH surge for the next postovulatory follicular wave. These associations between FSH surges and follicular waves in control heifers are based on the results of the cautery and follicular fluid studies. 
inverse profiles for 2-wave vs. 3-wave heifers. On Day 14, concentrations of FSH were maximum in 3 -wave heifers but minimum in 2-wave heifers $(P<0.01)$.

The FSH concentrations were high in 2-wave heifers on Day 0 (ovulation at beginning of the interovulatory interval) and Day 19 (day before next ovulation; mean interovulatory interval, 20 days) and in 3-wave heifers on Days 0 and 22 (day before ovulation at the end of the interovulatory interval; mean interovulatory interval, 23 days). A midcycle surge in FSH peaked in 2-wave heifers on Day 9 and the apparent surges in 3-wave heifers peaked on Days 8 and 14. A periovulatory surge in plasma FSH has been observed in other studies although some reported a primary surge coincident with the preovulatory LH surge and a secondary surge 18-24 h after the onset of the LH surge (Dobson, 1978; Walters \& Schallenberger, 1984; Quirk \& Fortune, 1986), whereas others reported only a primary surge (Akbar et al., 1974). The present study did not entail frequent sampling and did not encompass the entire periovulatory period for either the first or second ovulation of the interovulatory interval; therefore, double periovulatory peaks may have been missed.

Results of a recent study (Turzillo \& Fortune, 1990) using treatment with follicular fluid indicated that treatment during oestrus suppressed the latter part of the periovulatory FSH surge (apparent secondary surge), which resulted in delayed emergence of wave 1. Delaying the emergence of wave 1 (Turzillo \& Fortune, 1990) or wave 2 (Kastelic et al., 1990) by treatment with follicular fluid resulted in a greater proportion of heifers with 2- rather than 3-wave interovulatory intervals. Conversely, the proportion of heifers with more than two waves was greater $(P<0.05)$ than in controls, when the onset of wave 2 was hastened by follicle cautery (Ko et al., 1991) or treatment with follicular fluid (Kastelic et al., 1990).

The luteal-phase surges in circulating FSH detected in the present study were coincident with the static phases of anovulatory dominant follicles in both 2-wave and 3-wave interovulatory intervals (Fig. 5). Consequently, in examining the data from control heifers alone (Expt 3), it was not apparent whether the FSH surges were functionally associated with the follicular waves during which the FSH surges occurred or with the following follicular wave. The results of Expts 1 and 2, however, documented the temporal sequence between surges in FSH and the emergence of follicular waves; a surge in FSH necessarily preceded the emergence of a wave. The timing of FSH surges prior to the emergence of each wave was similar for treated (Expts 1 and 2) and control (Expt 3) heifers. On average, the FSH surge began and peaked 2 days and 1 day, respectively, before the ultrasonically detectable emergence of a follicular wave. In addition, the results indicated that the FSH surge was not functionally involved with the growth profile of the anovulatory dominant follicle with which it was temporally coincident. Suppression of the FSH surge by treatment with follicular fluid on Days 6-11 (coincident with the static phase of the dominant follicle of wave 1) had no effect on the diameter profile of the coincident dominant follicle.

Results did not support the concept, derived from temporal relationships (Ginther et al., $1989 \mathrm{c}$ ), that the emergence of a wave is responsible for the demise of the dominant follicle of the previous wave. Growing follicles stopped growing and started to regress 1 day and 5 days, respectively, after the start of treatment with follicular fluid, but the demise of static-phase or regressing follicles was not hastened (Kastelic et al., 1990). Suppression of FSH by follicular fluid could account for the suppression of growing follicles. Apparently the static phase of the dominant follicle became incapable of suppressing FSH and, thereby, allowed FSH to surge. The surge was closely followed by the recruitment of follicles of the next wave. The decline in FSH was rapid and began at the time of, or shortly after, the emergence of the follicular wave. The long-loop feedback system between the ovarian follicles and the pituitary gland may be extremely sensitive, resulting in suppression of FSH shortly (1-2 days) after detection of a follicular wave. On the other hand, the surge in plasma FSH may cause a temporary depletion of FSH in the pituitary, resulting in a rapid decline in plasma concentrations, which are subsequently maintained at low levels by factors (e.g. inhibin; Findlay \& Clarke, 1987) produced by the dominant follicle. In the face of basal concentrations of plasma FSH, subordinate follicles regressed, but the dominant follicle continued to 
grow. This result is consistent with the hypothesis that the dominant follicle is less dependent on FSH, or is more sensitive to available concentrations of FSH through increased induction of FSH receptors (Ireland, 1987; Ireland \& Roche, 1987). The latter is more consistent with present results; the growth of the dominant follicle was inhibited (Kastelic et al., 1990) by suppression of FSH (below basal concentrations; Fig. 3) by follicular fluid.

The time of selection of the dominant follicle of a wave (defined as the time of divergence in growth profiles of subordinate vs. dominant follicles) first became manifest retrospectively within 2 days of the detected emergence of a wave (Ginther et al., 1989c). The apparent time of the manifestation of follicle selection was coincident with the first significant drop in FSH concentrations. Further study is required to determine whether these two temporal events (drop in FSH concentration and selection of a dominant follicle) are functionally related.

This research was supported by the College of Agricultural and Life Sciences, University of Wisconsin, Madison. We thank D. J. Bolt of the USDA Animal Hormone Program for providing assay reagents, F. Wegner for assistance with the RIA procedure, L. Kulick for assistance with graphs and $\mathrm{M}$. Westphal for manuscript preparation.

\section{References}

Akbar, A.M., Reichert, L.E., Dunn, T.G., Kaltenback, C.C. \& Niswender, G.D. (1974) Serum levels of follicle stimulating hormone during the bovine estrous cycle. J. Anim. Sci. 39, 361-365.

Bolt, D.J. \& Rollins, R. (1983) Development and application of a radioimmunoassay for bovine follicle-stimulating hormone. J. Anim. Sci. 56, $146-154$

Butler, W.R., Katz, L.S., Arriola, J., Milvae, R.A. \& Foote, R.H. (1983) On the negative feedback regulation of gonadotropins in castrate and intact cattle with comparison of two FSH radioimmunoassays. $J$. Anim. Sci. 56, 919-929.

Cheng, K. (1978) Development and characterization of a homologous radioimmunoassay for bovine folliclestimulating hormone. J. Endocr. 77, 185-193.

de Kretser, D.M. \& Robertson, D.M. (1989) The isolation and physiology of inhibin and related proteins. Biol. Reprod. 40, 33-47.

Dobson, H. (1978) Plasma gonadotrophins and oestradiol during oestrus in the cow. $J$. Reprod. Fert. 52, 51-53.

Findlay, J.P. \& Clarke, I.J. (1987) Regulation of the secretion of FSH in domestic ruminants. $J$. Reprod. Fert. Suppl. 34, 27-37.

Ginther, O.J., Kastelic, J.P. \& Knopf, L. (1989a) Composition and characteristics of follicular waves during the bovine estrous cycle. Anim. Reprod. Sci. 20, 187-200.

Ginther, O.J., Kastelic, J.P. \& Knopf, L. (1989b) Intraovarian relationships among dominant and subordinate follicles and the corpus luteum in heifers. Theriogenology 32, 787.795 .

Ginther, O.J., Knopf, L. \& Kastelic, J.P. (1989c) Temporal associations among ovarian events in cattle during oestrous cycles with two and three follicular waves. J. Reprod. Fert. 87, 223-230.

Ireland, J.J. (1987) Control of follicular growth and development. J. Reprod. Fert. Suppl. 34, 39-54.

Ireland, J.J. \& Roche, J.F. (1987) Hypotheses regarding development of dominant follicles during a bovine estrous cycle. In Follicular Growth and Ovulation
Rate in Farm Animals, pp. 1-18. Eds J. F. Roche \& D. O'Callaghan. Martinus Nijhoff, Dordrecht.

Ireland, J.J., Curato, A.D. \& Wilson, J. (1983) Effect of charcoal-treated bovine follicular fluid on secretion of LH and FSH in ovariectomized heifers. J. Anim. Sci. 57, 1512-1516.

Johnson, S.K. \& Smith, M.F. (1985) Effects of charcoalextracted, bovine follicular fluid on gonadotropin concentrations, the onset of estrus and luteal function in heifers. J. Anim. Sci. 61, 203209.

Kastelic, J.P., Ko, J.C.H. \& Ginther, O.J. (1990) Suppression of dominant and subordinate ovarian follicles by a proteinaceous fraction of follicular fluid in heifers. Theriogenology 34, 499-509.

Knopf, L., Kastelic, J.P., Schallenberger, E. \& Ginther, O.J. (1989) Ovarian follicular dynamics in heifers: test of two-wave hypothesis by ultrasonically monitoring individual follicles. Dom. Anim. Endocr. 6, $111-119$.

Ko, J.C.H., Kastelic, J.P., Del Campo, M.R. \& Ginther, O.J. (199I) Effects of a dominant follicle on ovarian follicular dynamics during the oestrous cycle in heifers. J. Reprod. Fert. 91, 511-519.

Matteri, R.L., Roser, J.F., Baldwin, D.M., Lipovetshy, V. \& Papkoff, H. (1987) Characterization of a monoclonal antibody which detects luteinizing hormone from diverse mammalian species. Dom. Anim. Endocr. 4, 157-165.

Matton, P., Adelakoun, V., Couture, Y. \& Dufour, J.J. (1981) Growth and replacement of the bovine ovarian follicles during the estrous cycle. J. Anim. Sci. 52, 813-820.

Miller, K.F., Crister, J.K., Rowe, R.F. \& Ginther, O.J. (1979) Ovarian effects of bovine follicular fluid treatment in sheep and cattle. Biol. Reprod. 21, 537-544.

Quirk, S.M. \& Fortune, J.E. (1986) Plasma concentrations of gonadotrophins, preovulatory follicular development and luteal function associated with bovine follicular fluid-induced delay of oestrus in heifers. J. Reprod. Fert. 76, 609-621.

Downloaded from Bioscientifica.com at $04 / 26 / 2023$ 12:35:08PM via free access 
Robertson, D.M., Foulds, L.M., Leversha, L., Morgan, F.J., Hearn, M.T.W., Burger, H.G., Wettenhall, R.E.H. \& de Kretser, D.M. (1985) Isolation of inhibin from bovine follicular fluid. Biochem. Biophys. Res. Commun. 126, 220-226.

Roche, J.F. \& Ireland, J.J. (1981) The differential effect of progesterone on concentrations of luteinizing hormone and follicle-stimulating hormone in heifers. Endocrinology 108, 568-572.

Rodbard, D. (1974) Statistical quality control and routine data processing for radioimmunoassays and immunoradiometric assays. Clin. Chem. 20, $1255-1270$.

Rodbard, D. \& Lewald, J.E. (1970) Computer analysis of radioligand assay and radioimmunoassay data. In Karolinska Symposia on Research Methods in Reproductive Endocrinology, 2nd Symposium. Steroid assay by protein binding, pp. 79-103. Eds E. Diczfalusy \& A. Diczfalusy. Bogtrykkeriet Forum, Copenhagen.

Savio, J.D., Keenan, L., Boland, M.P. \& Roche, J.F. (1988) Pattern of growth of dominant follicles during the oestrous cycle of heifers. J. Reprod. Fert. 83, $663-671$.

Schallenberger, E., Schams, D., Bullerman, B. \& Walters, D.L. (1984) Pulsatile secretion of gonadotrophins, ovarian steroids and ovarian oxytocin during prostaglandin-induced regression of the corpus luteum in the cow. J. Reprod. Fert. 71, 493-501.
Schallenberger, E., Schöndorfer, A.M. \& Walters, D.L. (1985) Gonadotrophins and ovarian steroids in cattle I. Pulsatile changes of concentrations in the jugular vein throughout the oestrous cycle. Acta endocr., Copnh. 108, 312-321.

Schams, D. \& Schallenberger, E. (1976) Heterologous radioimmunoassay for bovine follicle stimulating hormone and its application during the estrous cycle in cattle. Acta endocr., Copnh. 86, 461-473.

Sirois, J. \& Fortune, J.E. (1988) Ovarian follicular dynamics during the estrous cycle in heifers monitored by real-time ultrasonography. Biol. Reprod. 39, 308-317.

Staigmiller, R.B. \& England, B.G. (1982) Folliculogenesis in the bovine. Theriogenology $17,42-52$.

Tonetta, S.A. \& deZerega, G.S. (1989) Intragonadal regulation of follicular maturation. Endocr. Rev. 10, 205-229.

Turzillo, A.M. \& Fortune, J.E. (1990) Suppression of the secondary FSH surge with bovine follicular fluid is associated with delayed ovarian follicular development in heifers. J. Reprod. Fert. 89, 643-653.

Walters, D.L. \& Schallenberger, E. (1984) Pulsatile secretion of gonadotrophins, ovarian steroids and ovarian oxytocin during the periovulatory phase of the oestrous cycle in the cow. J. Reprod. Fert. 71, 503-512.

Received 10 December 1990 